\title{
CONSTRUÇÃO DE UMA MATRIZ DE INDICADORES PARA A AVALIAÇÃO DE PROGRAMAS/ PROJESTOS DE EDUCAÇÃO AMBIENTAL EM SANEAMENTO: POSSIBILIDADES METODOLÓGICAS
}

Pollyana da Silva de Magalhães ${ }^{1}$

Sandra Maria Furiam Dias ${ }^{2}$

RESUMO: Esse estudo propõe uma metodologia pautada em estratégias participativas para a construção de uma matriz de indicadores para avaliação de programas/projetos de Educação Ambiental (EA) em saneamento. Para isso, conjugaram-se fundamentos teóricos e marcos legais de ambas as áreas a partir da construção, aplicação e validação de indicadores, com estratégias metodológicas onde, os interesses e percepções dos atores envolvidos em tais programas/projetos, pudessem ser conhecidos e eticamente negociados para que, assim, o rigor metodológico e os conhecimentos empíricos favoreçam o empoderamento dos envolvidos e, desse modo, a legitimidade e efetividade da avaliação. A presente proposta foi aplicada em um programa de EA para a gestão de resíduos sólidos desenvolvido em um município do semiárido baiano.

Palavras-chave: Educação Ambiental; Saneamento; Possibilidades Metodológicas; Construção de Indicadores; Avaliação de Programas/Projetos.

\footnotetext{
${ }^{1}$ Bióloga, especialista em educação ambiental, mestre em engenharia civil e ambiental pelo Programa de Pós-Graduação em Engenharia Civil e Ambiental do Departamento de Tecnologia da Universidade Estadual de Feira de Santana. E-mail: psmbio@hotmail.com.

2 Engenheira civil, doutora em Saúde Pública (USP), docente titular do departamento de tecnologia da Universidade Estadual de Feira de Santana, membro do corpo docente do Programa de Pós-Graduação em Engenharia Civil e Ambiental da UEFS. E-mail: smfuriam@uefs.br.
} 


\section{INTRODUÇÃO}

Apesar da Educação Ambiental (EA) ser reconhecidamente um dos instrumentos educativos mais relevantes no âmbito das ações de saneamento (MARANHÃO; SORRENTINO, 2009; WARTCHOW, 2009; LIMA, 2009), as intervenções conduzidas sob orientação dos programas do governo federal não têm apresentado impacto efetivo às problemáticas existentes no campo do saneamento (BRASIL, 2005). Dentre as várias justificativas, pode-se destacar a inconsistência e, até mesmo, falta de acompanhamento de um processo avaliativo para tais iniciativas (RIBEIRO; GUNTHER; ARAÚJO, 2002).

A baixa efetividade de tais ações sinaliza às fragilidades de processos avaliatórios que, quando existem, na maioria das vezes, têm adotado desenhos metodológicos pouco participativos e priorizado elementos quantitativos para, quase sempre, atender às exigências burocráticas de órgãos financiadores, em detrimento do aprendizado coletivo construído na dinamicidade do pensar, repensar e reorientar posturas e ações.

Nessa perspectiva, a avaliação de programas/ projetos socioambientais compromete seu caráter político e sua essência pedagógica para, caminhar na superficialidade de abordagem, implicando no descrédito ou até mesmo, no abandono desta prática. Outra consequência desse problema é a construção de sistemas de indicadores numerosos, não contextuais, pouco inteligíveis e, portanto, de difícil operacionalização por todos (as) os (as) interessados (as) (OAKLEY; CLAYTON, 2003).

Esse cenário sinaliza para a importância da inserção efetiva dos atores sociais no processo de avaliação das intervenções socioambientais das quais vivenciam. No entanto, esta não se configura em uma postura metodológica de fácil execução, haja vista que, junto aos benefícios desta prática, diversos desafios se impõem, como, por exemplo: traduzir os interesses e necessidades dos participantes de tais intervenções para uma linguagem relativamente recente, em se tratando da construção de indicadores.

Assim, esse trabalho propõe um possível caminho metodológico participativo para a construção de uma matriz de indicadores que poderá nortear à avaliação de programas/projetos de EA aplicados ao saneamento de um modo geral ou adaptado a avaliação de intervenções educacionais específicas relacionadas ao abastecimento de água, ao esgotamento sanitário, à gestão e o gerenciamento de resíduos sólidos ou ao manejo de águas pluviais.

O desenho metodológico sugerido foi plicado, por um ano e meio, em um programa de educação ambiental para a gestão de resíduos sólidos (PEAGRS), desenvolvido em um pequeno município do semiárido baiano, a partir do Fórum Permanente da Agenda 21 municipal. Tal programa tem como um de seus objetivos, a construção de um plano municipal participativo para a gestão de resíduos sólidos. 


\section{O PERCURSO METODOLÓGICO ADOTADO NA AVALIAÇÃO DO PROGRAMA DE EDUCAÇÃO AMBIENTAL PARA A GESTÃO DE RESÍDUOS SÓLIDOS}

Com o intuito de minimizar reducionismos de abordagens tanto teóricas quanto metodológicas, buscou-se conjugar fundamentos e pressupostos teóricos com conhecimentos empíricos vivenciados na prática do processo participativo de avaliação do PEAGRS.

Para a seleção do grupo de avaliadores (as), consideraram-se os seguintes critérios: desejo espontâneo de participar da avaliação e $75 \%$ de frequência nos primeiros cinco encontros observados do programa. Foram selecionados 14 atores, aqui denominados (as) de avaliadores (as) por terem atuado tanto na elaboração, na aplicação, quanto na validação interna da matriz de indicadores, mais 01 coordenadora do PEAGRS.

O grupo de avaliadores (as) foi constituído por 09 mulheres e 06 homens, com idades que variavam de 26 a 59 anos, 11 moradores da zona rural e 3 da zona urbana. Entre eles tinham representantes e membros de 8 associações de moradores rurais, do sindicato dos trabalhadores rurais do município, lavradores, uma professora do ensino fundamental, um comerciante, aposentados, funcionárias públicas da secretaria municipal de ação social e desempregados.

Quanto ao nível de escolaridade, o grupo apresentou 6 membros com ensino fundamental incompleto, $1 \mathrm{com}$ ensino médio incompleto, $4 \mathrm{com}$ ensino médio completo, 2 com nível superior incompleto e 2 pós-graduados. A renda da maioria situou-se na escala de 1 a 3 salários mínimos, estando 2 deles sem renda.

Apesar do baixo nível de escolaridade, muitos dos atores, apresentaram uma retórica clara, demonstrada pela espontaneidade e facilidade em se expressar, fundamentada a partir de experiências vivenciadas em outros espaços de discussão dos quais também são líderes e/ou membros.

A investigação foi dividida em quatro etapas principais: (i) Construção da Matriz preliminar de indicadores; (ii) Validação Externa da Matriz; (iii) Aplicação da matriz na avaliação do PEAGRS e (iv)Validação interna da matriz durante a avaliação no referido programa. Os métodos e técnicas adotados em cada etapa descrita estão apresentados na Figura 1 e serão posteriormente explicados. 


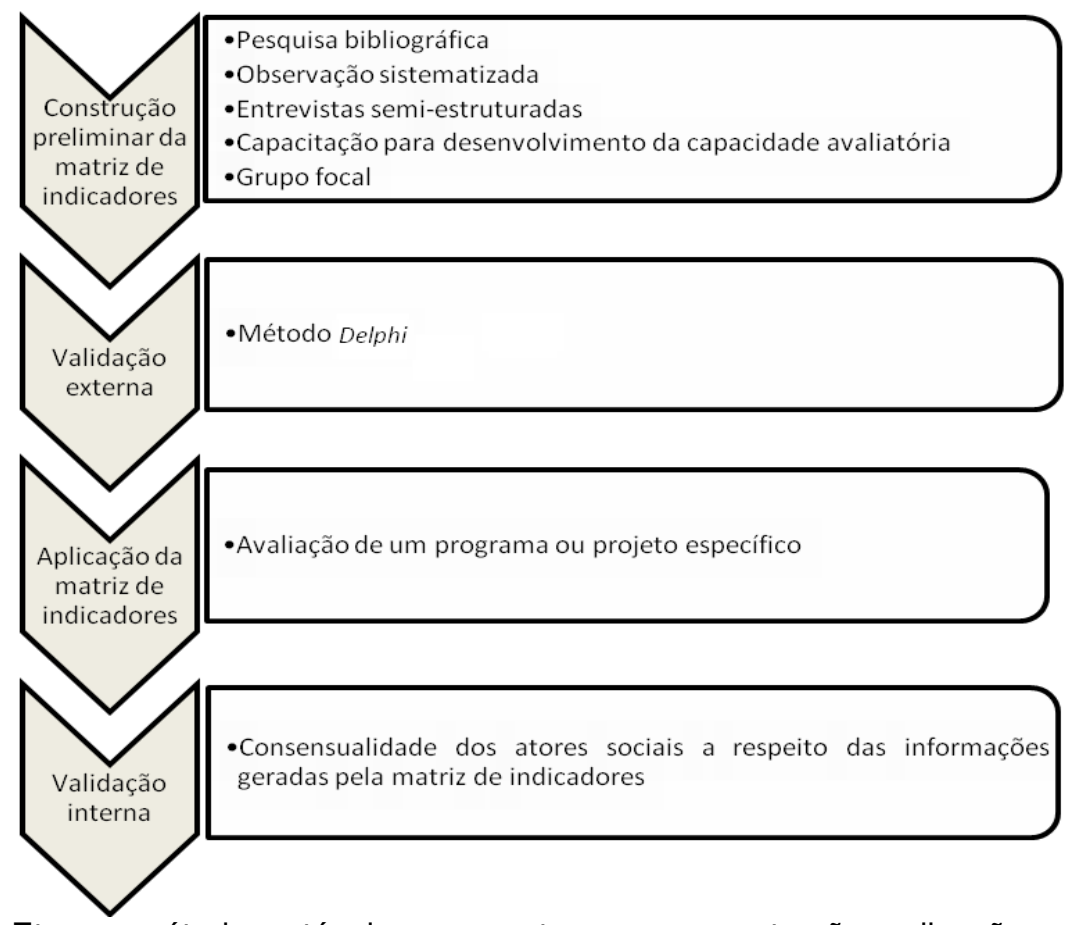

Figura 1: Etapas, métodos e técnicas propostos para a construção, aplicação e validação da Matriz de Indicadores de avaliação de Programas/projetos de Educação Ambiental em saneamento.

\section{Etapa 1 - Construção da matriz preliminar de indicadores}

A versão preliminar da matriz de indicadores deve ser construída a partir da conjugação de métodos e técnicas que se complementem, seja na confirmação e no esclarecimento dos dados coletados ou na minimização das limitações que cada uma delas apresenta para, então, permitir uma aproximação gradual do objeto avaliado. Assim, sugere-se a seguinte composição:

\section{- Pesquisa bibliográfica}

Como instrumentos norteadores das concepções teóricas e metodológicas a serem adotadas na construção e validação da matriz de indicadores sugerem-se, principalmente, 0 estudo dos marcos legais $e$ documentos oficiais relacionados à EA e ao saneamento, a saber: Lei $n^{\circ}$ 9.795/99 que institui a Política Nacional de Educação Ambiental (PNEA); Lei $n^{\circ}$ 11.445/07 que estabelece as diretrizes nacionais para o saneamento básico e para a Política Federal de Saneamento e seu regulamento Decreto oํ 7217/10; Lei $n^{\circ} 12.305 / 2010$ que institui a Política Nacional de Resíduos Sólidos e o Decreto $n^{\circ} 7404 / 2010$ que regulamenta a referida política; O Programa Nacional de Educação Ambiental ; Documento de referência conceitual do Programa de Educação Ambiental e Mobilização Social para o Saneamento (PEAMSS); Caderno metodológico do programa de educação ambiental e mobilização social para o saneamento (PEAMSS), Resolução $n^{\circ} 422$ do Conselho Nacional de Meio Ambiente (CONAMA) de 23 de março de 2010 que Revbea, Rio Grande, V. 8, N² 2:47-62, 2013. 
estabelece as diretrizes para campanhas, ações e projetos de EA. Também devem ser consultadas as literaturas pertinentes aos seguintes temas: saneamento, EA, indicadores, avaliação de programas/projetos sociais e de políticas públicas.

\section{- Observação sistematizada}

Com o intuito de buscar aproximação do contexto investigado e, com isso, identificar elementos que sinalizem para aspectos relevantes a serem considerados na construção da matriz, sugere-se que se proceda a uma observação sistematizada. Trata-se de uma das técnicas mais utilizadas na pesquisa qualitativa, em que o(a) pesquisador(a) faz uso dos órgãos dos sentidos para conhecer a realidade investigada (SANTANA, 2003, p.13). No entanto, para minimizar as subjetividades de interpretação construídas a partir das particularidades existentes nas visões de mundo de cada pesquisador(a), a autora sugere que a observação "seja planejada e sistematizada, precedida de um planejamento e preparação do observador, que deverá ter claro "o que" e "como" pesquisar".

Os elementos a serem observados dependerão das especificidades de cada programa e/ou projeto e também de qual das ações de saneamento está sendo aplicado, no que se referem a seu planejamento, processo de execução, resultados e impactos.

No caso do PEAGRS foram sistematicamente observados cinco tópicos:

I. Dados gerais do programa (Data, local, duração, temáticas trabalhadas, objetivos de cada encontro); II. Logística (frequência dos participantes, segmentos sociais representados, estratégias de divulgação dos encontros, forma de disposição dos assentos, qualidade da iluminação e ventilação local, conforto auditivo, recursos didáticos e audiovisuais utilizados, suficiência do tempo disponível para o desenvolvimento das atividades, acessibilidade ao local dos encontros); III. Perfil pedagógico do(a) educador(a) ambiental (competência científico-pedagógica, clareza, objetividade e adequação da linguagem utilizada, estímulo à autonomia do grupo, sensibilidade quanto às necessidades do grupo, assiduidade, pontualidade); IV . Desenhos e instrumentos metodológicos (coerência entre os métodos e técnicas utilizados com os objetivos propostos, flexibilidade metodológica de acordo as necessidades do grupo; competências e habilidades desenvolvidas, prática de avaliação); V. Dinâmica do grupo de atores do PEAGRS (relações interpessoais, negociação de interesses e conflitos, capacidade de iniciativa, liderança, interação do grupo com o(a) educador(a) ambiental).

\section{- Entrevistas semiestruturadas individuais}

Com a análise e interpretação dos dados coletados na etapa anterior, busca-se, então conhecer, individualmente, as concepções dos envolvidos nos programas/projetos sobre as potencialidades e fragilidades do programa/projeto avaliado. Para isso, os mesmos devem ser entrevistados. 
Para Cervo, Bervian e da Silva (2006, p.51) a entrevista é uma conversa orientada com um objetivo definido, que é o de realizar um levantamento de dados para a pesquisa. Complementando essa definição, Minayo (1993) sinaliza que a referida técnica deve facilitar a abertura, ampliação e o aprofundamento da comunicação. Uma das modalidades desta técnica é a entrevista semiestruturada, que combina perguntas fechadas (ou estruturadas) e abertas, onde o(a) entrevistado(a) discorre sobre o tema proposto sem respostas ou condições pré-fixadas pelo(a) pesquisador(a) (MINAYO, 1993).

Observados os aspectos éticos como anonimato e sigilo, essa técnica favorece a confiabilidade dos dados coletados, já que, os atores conversam em particular com o(a) pesquisador(a) e geralmente colocam fatos e opiniões que, normalmente, não fariam publicamente.

Para entrevistar os atores do PEAGRS foi elaborado um roteiro de entrevista com 03 tópicos: I. Perfil socioeconômico do ator (nome, sexo, idade, naturalidade, nacionalidade, estado civil, localidade, escolaridade, profissão, renda); II. Sobre o PEAGRS (interesse em participar do programa, conhecimento a respeito dos objetivos do programa, formas de participação, critérios de distribuição de tarefas no grupo, valorização de opiniões, relacionamento com o grupo, nível de entendimento dos temas abordados, conhecimentos construídos e utilizados no cotidiano, potencialidades e fragilidades do PEAGRS; III. Conhecimentos específicos a respeito dos resíduos sólidos (diferença entre lixo e resíduo sólido, informações sobre o gerenciamento dos resíduos sólidos da localidade em que mora, destino final, órgão responsável, como maneja os resíduos do domicílio, presença de catadores, estratégias para diminuir a geração de resíduos, problemas ambientais e de saúde pública causados pelo contato direto ou indireto com resíduos).

\section{- Capacitação para o desenvolvimento da capacidade avaliatória:}

Para perseguir a efetividade na participação dos atores sociais implicados na avaliação de programas/projetos de EA em saneamento deve-se considerar o caráter político e pedagógico de tal processo. Então, faz-se necessário que o desenvolvimento da capacidade avaliatória dos atores sociais seja estimulado, haja vista que, os termos técnicos no campo dos indicadores são, comumente, pouco familiares aos mesmos. Nesse sentido, concorda-se com Penna Firme (2011, p.2) quando a autora afirma que

O grande desafio nesta era contemporânea da informação não é a capacidade de produzir, armazenar ou transmitir informações, mas sim reconhecer o que é importante saber e, de fato, utilizar essa informação. Nessa perspectiva, a questão crucial é descobrir o que é preciso fazer para criar e desenvolver avaliações que sejam realmente utilizadas para reduzir incertezas, melhorar a efetividade e tomar decisões relevantes.

Revbea, Rio Grande, V. 8, № 2:47-62, 2013. 
Nesse olhar, os atores devem ser instrumentalizados para discutir e negociar seus conceitos sobre avaliação, focos, objetivos e aspectos éticos a serem adotados no processo avaliativo. Assim, durante a capacitação para o desenvolvimento da capacidade avaliatória dos atores do PEAGRS, foram abordados, de forma crítica, os seguintes temas:

- Avaliação de programas/projetos socioambientais;

- A complexidade que envolve os programas/projetos socioambientais, sob uma perspectiva sistêmica que considera as dimensões sociais, políticas, educacionais, culturais e econômicas;

- Intervenções de EA em saneamento;

- Conceitos, utilidades e metodologias de construção e aplicação de indicadores.

Para trabalhar cada um dos temas apresentados foram construídos, respectivamente, quatro módulos didáticos com uma variedade de exercícios práticos de problematização, interpretação de imagens, textos de sensibilização, estudos de caso de avaliação de projetos socioambientais, análise de materiais didáticos relacionados à gestão de resíduos, dentre outros. Os temas centrais e principais tópicos abordados nos referidos módulos estão apresentados no Quadro I (próxima página).

Quadro I: Temas centrais e tópicos abordados nos quatro módulos didáticos trabalhados durante a capacitação para o desenvolvimento da capacidade avaliatória dos atores do PEAGRS

\begin{tabular}{|c|c|c|}
\hline MÓDULO & TEMA CENTRAL & TÓPICOS ABORDADOS \\
\hline I & $\begin{array}{l}\text { O que entendemos por } \\
\text { avaliação de } \\
\text { programas/projetos } \\
\text { socioambientais? }\end{array}$ & $\begin{array}{l}\text { 1. Discutindo e construindo o conceito de avaliação do nosso } \\
\text { grupo; } 2 \text {. Principais tipos de avaliação; 3. Um pouco da história } \\
\text { da avaliação das políticas públicas; } 4 \text {. Objetivos da avaliação; } \\
\text { 5. A ética no processo de avaliação. }\end{array}$ \\
\hline II & $\begin{array}{l}\text { A complexidade que } \\
\text { envolve a avaliação de } \\
\text { programas e projetos } \\
\text { socioambientais }\end{array}$ & $\begin{array}{l}\text { 1.O que é complexidade?; } 2 \text {. Dimensões que envolvem um } \\
\text { projeto socioambiental e sua avaliação; } 3 \text {. A importância da } \\
\text { diversidade de ideias na avaliação participativa; } 4.0 \\
\text { pensamento complexo: visão das partes e do todo; } 5 \text {. Para } \\
\text { avaliar é preciso chegar perto. }\end{array}$ \\
\hline III & $\begin{array}{l}\text { Educação Ambiental no } \\
\text { Saneamento: } \\
\text { conhecendo princípios e } \\
\text { avaliando ações }\end{array}$ & $\begin{array}{l}\text { 1.Porque ações educativas para o saneamento? 2. Educação } \\
\text { Ambiental e Saneamento: alguns pontos tratados pelas leis } \\
\text { e/ou documentos oficiais; 3. O Programa de Educação } \\
\text { Ambiental e Mobilização Social em Saneamento; } 4 \text {. Avaliando } \\
\text { uma avaliação de educação ambiental em saneamento. }\end{array}$ \\
\hline IV & $\begin{array}{l}\text { Construindo indicadores } \\
\text { para avaliação de } \\
\text { programas/projetos } \\
\text { socioambientais }\end{array}$ & $\begin{array}{l}\text { 1.O que são e para que servem os indicadores? 2. Breve } \\
\text { história dos indicadores; } 3 \text {. Tipos de indicadores; } 4 \text {. } \\
\text { Características essenciais de um sistema de indicadores; } 5.0 \\
\text { que podem e o que não podem fazer os indicadores? } 6 . \\
\text { Construindo perguntas avaliativas; } 7 . \text { Como construir } \\
\text { indicadores. }\end{array}$ \\
\hline
\end{tabular}


Sobre esse aspecto, é fundamental que todos os temas sugeridos sejam abordados a partir de estratégias metodológicas problematizadoras e estimulantes, com linguagem adequada ao público, contribuindo, desse modo, para o desenvolvimento da criticidade necessária para o aperfeiçoamento das capacidades de identificar problemas, propor encaminhamentos e executar 0 controle social das ações durante todo o processo avaliativo.

Em síntese, a análise coletiva do curso de capacitação para o desenvolvimento da capacidade avaliatória dos atores do PEAGRS permitiu observar que os atores tiveram uma participação satisfatória em todas as vivências e discussões propostas/negociadas nos três primeiros encontros, onde o clima de tensão inicial, comum em ambientes de avaliação, foi sendo, gradativamente transformado, em um ambiente de descontração, interação e cooperação. Entretanto, no segundo bloco do último encontro, observou-se que parte do grupo não respondeu de modo esperado à exposição prolongada dos últimos tópicos, que tratava de diversos conceitos ligados a construção de indicadores. O referido problema foi minimizado no primeiro encontro do grupo focal no qual a discussão de alguns termos e conceitos foi retomada.

Desse modo, esta foi uma etapa fundamental dessa pesquisa, pois, além de ampliar a compreensão dos eixos temáticos que constituem o presente trabalho, foram momentos de autoconhecimento para o grupo e aproximação do contexto investigado pela pesquisadora. Algumas das limitações do processo de aprendizagem identificadas e descritas nessa sessão fazem parte do conhecimento e desenvolvimento do grupo, bem como, do aperfeiçoamento metodológico dessa pesquisa.

\section{- Grupo focal}

É uma técnica de pesquisa que tem como principal característica a produção do conhecimento a partir da interação entre pessoas que vivenciam uma problemática semelhante. Segundo Ressel e outros (2008, p.780) essa técnica é "adequada para a avaliação de programas ou projetos que visem, dentre outras coisas, identificar problemas educativos em saúde". Trata-se de uma estratégia utilizada para captação de informações sobre um determinado acontecimento vivenciado ou conhecido por um grupo de sujeitos que discutem livremente sobre um determinado assunto, com o auxílio de um moderador, ao receberem estímulos apropriados para o debate (SANTANA, 2003).

Kitzinger (1999) citado por Ressel e outros (2008, p.780) considera ainda que a referida técnica permita ao pesquisador não só examinar as diferentes análises dos sujeitos em relação a um assunto específico, ele também proporciona explorar como os fatos são articulados, censurados, confrontados e alterados por intermédio da interação grupal. Esse ambiente é desejado em um processo de avaliação coletivo onde, deve-se proceder as negociações necessárias para se delimitar o foco da avaliação e assim, construir as perguntas avaliatórias que servirão posteriormente de subsídio para a construção dos indicadores. 
A referida técnica funciona, resumidamente, da seguinte forma: um(a) mediador(a) provoca os atores com recursos didáticos vários para que as discussões sejam focadas no tema de interesse e, então, observa como acontecem às interações entre os diálogos dos atores e que concepções, conflitos e interesses essas revelam. As discussões podem ser divididas em sessões com duração que varia entre 1 a 3 horas e deve ser feita com um mínimo de 4 e máximo de 15 pessoas para que seja estimulada a participação de todos os envolvidos.

O grupo focal (G.F.) realizado durante a avaliação do PEAGRS foi executado com 14 avaliadores(as) em quatro sessões com duração média de duas horas e meia e, teve como principal objetivo, amadurecer as reflexões levantadas durante a capacitação, para assim, construir o esboço da matriz de indicadores para a avaliação do PEAGRS, a partir de elementos identificados na interação dos diálogos entre dos avaliadores. Nesse sentido, as sessões foram divididas em três blocos temáticos (BT) como os respectivos objetivos:

- BT-01 /Sessões 01 e 02 - O foco da avaliação: construção das perguntas avaliatórias para o PEAGRS - definir o foco da avaliação do PEAGRS a partir da construção das perguntas avaliatórias;

- BT-02 / Sessão 03 - Construção do esboço da matriz de indicadores para avaliação do PEAGRS - construir um esboço da matriz de indicadores para avaliação do PEAGRS.

- BT-03/Sessão 04 - Inserção dos indicadores na matriz - inserir os indicadores construídos na matriz (dimensão, meios de verificação, descritores). Cada bloco temático foi constituído de questões-chave que nortearam as discussões.

Ao final das sessões do G.F., um esboço da versão preliminar da matriz de indicadores foi construída com 7 dimensões (social, política, educacional, cultural, ambiental, econômica e organização do espaço de diálogo) e 22 indicadores com seus respectivos elementos: perguntas norteadoras, descritores e meios de verificação.

Essa etapa foi bastante fecunda para a construção dos indicadores, visto que, são justamente nesses momentos, que um processo de investigação onde se arriscam possibilidades, testam-se conceitos e alinham-se compreensões em um processo democrático de negociação contribui para aprendizagem coletiva (BRANDÃO, 2007).

\section{Etapa 2 - Validação Externa da Matriz de Indicadores}

Uma vez construída, a matriz preliminar de indicadores, esta poderá ser submetida à validação externa a partir do método Delphi que, para Minayo (2009, p.88) é um dos instrumentos mais utilizados na construção de indicadores com abordagem qualitativa e tem um valor fundamental para validação tanto dos instrumentos como dos resultados da investigação, visto que, apresenta o reconhecimento do juízo de pessoas experientes sobre um determinado tema.

revista brasileira educação ambiental 
Tal método consiste em conhecer o nível de consensualidade de especialistas acadêmicos ou de pessoas com vivências práticas a respeito de um tema específico, no caso do presente estudo, tais especialistas deverão ser dos campos do saneamento, da EA e da avaliação de programas/projetos a partir da construção de indicadores. Tanto o número de especialistas quanto o percentual de consensualidade para validação variam substancialmente na literatura. Existem trabalhos com apenas 3 especialistas enquanto outros apresentam mais de uma centena.

O Painel Delphi para avaliação do PEAGRS foi composto por um grupo multidisciplinar de 11 juízes especialistas com suas identidades preservadas de acordo aos princípios de sigilo e anonimato acordados no termo de consentimento livre e esclarecido. Desse modo, usou-se o seguinte pseudônimo: $E_{x}$, onde $\mathrm{E}$ significa especialista $\mathrm{e} \mathrm{X}$ o número que o identifica no grupo.

O Quadro 2 apresenta a formação profissional, instituição que representam, e as áreas de atuação segundo os respectivos currículos divulgados na base de dados da Plataforma Lattes/ do Conselho Nacional de Desenvolvimento Científico e Tecnológico (CNPq).

Quadro 2: Perfil dos juízes especialistas que compuseram o Painel Delphi

\begin{tabular}{|c|c|c|c|}
\hline Especialistas (E) & Formação profissional & Instituição* & Área(s) de atuação \\
\hline$E_{1}$ & $\begin{array}{l}\text { Filosofia, Doutorado em } \\
\text { Educação }\end{array}$ & FURG & EA e Complexidade. \\
\hline$E_{2}$ & $\begin{array}{c}\text { Biologia, } \\
\text { Doutorado em Serviço Social }\end{array}$ & UFRJ & $\begin{array}{l}\text { EA em movimentos sociais e gestão } \\
\text { pública. }\end{array}$ \\
\hline$E_{3}$ & $\begin{array}{l}\text { Geografia, Doutorado em } \\
\text { Geografia Física }\end{array}$ & USP & $\begin{array}{c}\text { Política, planejamento e gestão } \\
\text { ambiental, saneamento ambiental, } \\
\text { coleta de lixo/ } \\
\text { Indicadores. }\end{array}$ \\
\hline $\mathrm{E}_{4}$ & $\begin{array}{l}\text { Eng. Civil, } \\
\text { Doutorado em Engenharia Civil }\end{array}$ & UFV & Saneamento Ambiental. \\
\hline$E_{5}$ & $\begin{array}{c}\text { Eng. de produção, Doutorado em } \\
\text { Eng. de produção }\end{array}$ & FURG & $\begin{array}{l}\text { Saneamento Ambiental / Gestão e } \\
\text { gerenciamento de Resíduos Sólidos }\end{array}$ \\
\hline$E_{6}$ & $\begin{array}{c}\text { Biologia, Mestre em Eng. Civil e } \\
\text { Ambiental }\end{array}$ & UEFS & $\begin{array}{c}\text { EA aplicada a Gestão de Resíduos } \\
\text { Sólidos }\end{array}$ \\
\hline$E_{7}$ & $\begin{array}{l}\text { Sociologia, Doutorado em } \\
\text { Sociologia }\end{array}$ & USP & $\begin{array}{l}\text { EA, Políticas Públicas e Gestão de } \\
\text { Resíduos Sólidos. }\end{array}$ \\
\hline$E_{8}$ & $\begin{array}{l}\text { Eng. Civil, doutorado em Saúde } \\
\text { Ambiental }\end{array}$ & UFBA & $\begin{array}{l}\text { Gestão dos serviços públicos de } \\
\text { saneamento básico. }\end{array}$ \\
\hline$E_{9}$ & $\begin{array}{c}\text { Administração pública, Mestre em } \\
\text { Ciências Ambientais }\end{array}$ & FGV-RJ & $\begin{array}{c}\text { Administração e gestão de recursos } \\
\text { hídricos. }\end{array}$ \\
\hline$E_{10}$ & $\begin{array}{l}\text { Eng. Sanitária, Doutorado em } \\
\text { Saúde Pública }\end{array}$ & IFPA & $\begin{array}{l}\text { Política e gestão em saneamento } \\
\text { ambiental. }\end{array}$ \\
\hline$E_{11}$ & $\begin{array}{c}\text { Assistência Social } \\
\text { Doutorado em Saúde Pública } \\
\text { Livre docência em Educação em } \\
\text { Saúde Ambiental }\end{array}$ & USP & $\begin{array}{l}\text { Promoção de Saúde e Políticas } \\
\text { Públicas, Educação em Saúde e } \\
\text { Educação Ambiental }\end{array}$ \\
\hline
\end{tabular}

*FURG: Universidade Federal do Rio Grande; UFRJ: Universidade Federal do Rio de Janeiro; USP: Universidade de São Paulo; UFV: Universidade Federal de Viçosa; UEFS: Universidade Estadual de Feira de Santana; UFBA: Universidade Federal da Bahia; FGV-RJ: Fundação Getúlio Vargas do Rio de Janeiro; IFPA: Instituto Federal do Pará. 
Apesar das áreas de atuação dos especialistas serem semelhantes (EA e/ou saneamento) a formação acadêmica no nível de graduação dos mesmos foi bastante diversa como demonstra o Quadro 2, o que, acreditou-se ter contribuído substancialmente com a busca de uma avaliação onde a diversidade de olhares aponte não só para os aspectos globais, mas para os específicos do instrumento submetido à validação externa.

Os parâmetros de validação dos indicadores também variam com níveis de consensualidade entre 50 a $85 \%$. Uma vez escolhido o percentual de validação, valores inferiores a este implicarão na reformulação do(s) indicador (es) ou até mesmo, em sua(s) exclusão(es) da matriz.

Caso não seja atingido o nível de consensualidade para a validação dos indicadores, outras consultas aos especialistas (rodadas) podem ser realizadas para alcançar esse objetivo. Tais consultas podem ser executadas por meio de correio eletrônico ou pessoalmente. Nos casos de indicadores qualitativos, geralmente mais complexos, a experiência mostra que é mais adequado reduzir o número de especialistas e, se possível for, executar as rodadas pessoalmente para, minimizar os erros de interpretação, evitar que campos de validação dos formulários ou planilhas não sejam preenchidos e facilitar a análise do instrumento submetido à validação, a partir do diálogo entre pesquisador e especialista em tempo real.

Sobre o processo de validação externa do PEAGRS, optou-se por um nível de consensualidade de $80 \%$ para considerar validado um indicador. Os critérios de validação foram baseados em 05 atributos adaptados de Silva (2005, p.51): efetivo, relevante, contextual, inteligível e exequível. Após o julgamento dos especialistas, a matriz de indicadores manteve a mesma configuração da matriz preliminar, no que se refere à estruturação em dimensões, indicadores, perguntas norteadoras, descritores e meios de verificação. As principais alterações relacionaram-se com a invalidação e, portanto, exclusão de um dos indicadores, bem como, a inserção e/ou modificações de perguntas norteadoras, sugestões e alterações em alguns dos descritores e associação de mais de um meio de verificação para o mesmo indicador.

Cabe ressaltar que validação ou invalidação de um indicador é aqui entendida como uma análise a ser complementada ou reconsiderada durante o processo de aplicação da matriz. Portanto, não se configura em uma classificação inflexível ou estanque, haja vista que, o instrumento construído é, obviamente, passível de aperfeiçoamento constante para atender às demandas diversas em contextos vários.

\section{Etapa 3 - Aplicação da Matriz de Indicadores}

Após a validação externa, a matriz de indicadores deverá finalmente ser aplicada na avaliação de um programa e/ou projeto específico. Esta é uma etapa muito importante, pois, permite testar se, a matriz construída, contempla os critérios que um eficiente sistema de indicadores deve apresentar e, 
principalmente, conhecer em que medida as informações geradas pelo sistema de indicadores construídos contribuíram efetivamente para a reorientação das práticas que favorecem o aprendizado coletivo e o empoderamento do grupo de avaliadores (as).

Para uma melhor observação dos consensos e dissensos do processo avaliativo e enriquecimento do debate durante a aplicação da matriz, julga-se didática a valoração cromatográfica de cada indicador adaptada de Ribeiro e Kaloustian (2007, p.9), já que, sempre que possível, a análise verbal e a interpretação dos indicadores devem ser reduzidas a algum tipo de diagrama visual, pois, o registro das descrições e observações pode ser uma tarefa ingrata para certos atores do programa, sendo mais adequado a uns do que a outros (OAKLEY; CLAYTON, 2003, p.48).

Tal técnica consiste em atribuir cores às perguntas norteadoras dos indicadores de acordo ao julgamento das informações por elas geradas. Desse modo, a cor verde simboliza que determinada ação ou situação é favorável ao desenvolvimento do programa/projeto avaliado, a cor amarela representava uma condição intermediária entre o desejável e o indesejável para um referido aspecto, a cor vermelha sinaliza que determinada ação deve ser executada ou reorientada e, finalmente, nos casos de abstenções, utiliza-se a cor branca.

Cabe ressaltar que a atribuição de cores aos indicadores não se configura em simples estratégia didática para que os atores visualizem uma síntese geral dos "resultados" da avaliação, mas, principalmente, para provocar a revelação de consensos e dissensos existentes, acompanhados das respectivas argumentações para que, a partir daí, novas proposições reorientem as práticas na direção do desenvolvimento do programa/projeto avaliado e dos atores que delem participam.

\section{Etapa 4 - Validação Interna da Matriz de Indicadores}

Finalmente, as informações geradas na etapa anterior irão subsidiar a validação interna da matriz de indicadores e das informações por ela produzidas por pessoas que estão diretamente envolvidas com o programa e/ou projeto a ser avaliado. Os critérios de validação devem ser negociados com o grupo para considerar em que medida o sistema de indicadores construído e aplicado foi capaz de gerar informações relevantes para o processo avaliativo. Para a validação do PEAGRS utilizou-se o seguinte questionamento: você acha que as informações geradas pelo indicador " $X$ " foram importantes para a avaliação do programa?

Para que os atores respondessem, utilizou-se tarjetas nas cores verde (sim), amarela (em parte) e vermelha (não). O nível de consensualidade adotado para a validação interna pode ser o mesmo selecionado para a validação externa, assim, adotou-se o nível de consensualidade dos atores de $80 \%$ para considerar validados internamente um indicador. Em relação à validação da matriz de indicadores para avaliação do PEAGRS obteve-se um nível de consensualidade de 100\%. 
Apesar de uma validação interna ter atingido a totalidade dos consensos, é a prática de construção e operacionalização da matriz de indicadores, aplicada em uma realidade específica, que demandará a inserção, reestruturação e até mesmo exclusão de indicadores do sistema, contribuindo assim, para o amadurecimento crítico que todo o grupo de avaliadores(as) precisa vivenciar.

\section{CONSIDERAÇÕES FINAIS}

Cada etapa metodológica aqui proposta para a construção, aplicação e validação da matriz de indicadores pode ser comparada com os vários níveis do zoom de uma câmara fotográfica, já que estes são mecanismos para se obter desde uma visão panorâmica até os menores detalhes da imagem que captura. Analogicamente ao contexto da avaliação de programas/projetos, esse processo é denominado por Brant (2007) em entrevista a Brandão (2007, p.61) de aproximação cumulativa do objeto de avaliado.

Assim, a observação sistematizada se constitui no contato inicial com o objeto de estudo, com o mínimo de interação, visto que se observa a certa distância e em silêncio. Nessa etapa, podem ser identificados os primeiros aspectos e ou elementos, possivelmente, ainda obscuros, soltos, sem muitas conexões que, ainda assim, servirão de substrato para potenciais indicadores a serem construídos $\left(1^{\circ} \mathrm{zoom}\right)$.

Em seguida, as entrevistas semi-estruturadas individuais se prestam a uma aproximação maior das concepções dos atores implicados no programa/projeto avaliado, a respeito das potencialidades e fragilidades do mesmo, onde, negociadas as garantias de sigilo e anonimato, espera-se que os dados coletados tenham um maior nível de confiabilidade, já que, em ambiente reservado, os atores podem fazer relatos que, normalmente, não o fariam publicamente. $\left(2^{\circ} \mathrm{zoom}\right)$.

Após a etapa anterior, comumente, tem-se um conjunto de elementos que pode iniciar o processo de construção da matriz de indicadores, no entanto, para se estimular a efetividade da participação dos atores no referido processo, julga-se necessária uma capacitação para o desenvolvimento da capacidade avaliatória dos atores. Aqui, busca-se conhecer, com maior proximidade, os diversos conceitos de avaliação que permeiam o entendimento do grupo, normalmente moldados por vivências prazerosas ou não do cotidiano desses atores, além de discutir a complexidade que envolve os processos avaliativos de projetos socioambientais semelhantes ao avaliado, tudo isso traduzido em uma linguagem relativamente recente no campo da avaliação (a dos indicadores) $\left(3^{\circ} \mathrm{zoom}\right)$.

A esta altura, espera-se que certo amadurecimento do grupo de avaliadores (as) no que concerne tanto a negociação e compreensão de conceitos quanto à construção de um ambiente de confiança propiciem uma interação maior dos diálogos onde tais conceitos continuem a ser questionados e reconstruídos para que, então, esse cenário se configure em um ambiente 
propício e fecundo para começar a discutir coletivamente as fragilidades e potencialidades do programa avaliado que subsidiarão a construção das perguntas norteadoras e, por sua vez, a construção dos indicadores nas sessões do(s) grupo(s) focal (is) ( $\left.4^{\circ} \mathrm{zoom}\right)$.

O $5^{\circ}$, mas não último zoom pode ser realizado durante a aplicação $e$ validação da matriz. Tal etapa metodológica busca capturar a síntese do processo de aprendizagem construído em parte, nas etapas anteriores, revelando as fragilidades e potencialidades não só do objeto avaliado, mas como do próprio processo avaliativo que, na analogia apresentada, representa a câmara fotográfica. Assim, há de se considerar os "defeitos" apresentados por esse "equipamento", na medida em que eles são identificados na prática.

Além dos mecanismos de aproximação do zoom, cabe aqui outra analogia ainda relacionada à câmara fotográfica, desta vez considerando a dimensão temporal. Como tal equipamento pode capturar imagens diferentes de uma mesma pessoa ao longo do tempo, os indicadores certamente produzirão informações diversificadas em períodos diferentes. São justamente essas diferenças que sinalizarão os avanços, estagnações e retrocessos do programa/projeto avaliado, alimentando desse modo, um processo dinâmico e contínuo de aprendizagem que uma avaliação que se diz pedagógica deve oportunizar.

Nesse olhar, o presente estudo defende que o caminho metodológico a ser traçado em qualquer processo avaliativo de programas e/ou projetos socioambientais aplicados ao saneamento deve ser pensado, refletido e executado coletivamente pelos envolvidos. Nesse sentido, as estratégias metodológicas aqui apresentadas se configuram em um esboço que pode e deve sofrer as alterações e adaptações que, porventura, os (as) avaliadores (as) julgarem necessárias em resposta às demandas de realidades específicas.

Com as vivências dos processos de construção, aplicação e validação interna da matriz de indicadores para a avaliação do PEAGRS, os (as) avaliadores (as) consideraram que, apesar do programa investigado se encontrar em um estágio embrionário de desenvolvimento, deveria ter apresentado resultados concretos, já que suas atividades tiveram início há aproximadamente um ano e meio atrás.

Os (as) avaliadores (as) ressaltaram ainda que a falta de concretude das ações propostas pode estar associada a um incipiente diálogo entre os membros do PEAGRS e os representantes dos setores públicos municipais responsáveis pela gestão de resíduos sólidos, já que este se encontra na informalidade, necessitando, desse modo, de sistematização e encaminhamento das propostas aos setores responsáveis, para, assim, favorecer o processo de controle social.

Dentre as potencialidades do PEAGRS, o grupo reconhece que, nesse período, tanto as atividades desenvolvidas quanto o processo avaliativo contribuíram para o amadurecimento do grupo no que se refere ao desenvolvimento das capacidades de iniciativa, de participação, de 
cooperação, de formulação de perguntas avaliatórias e de resolução de problemas que dizem respeito ao programa que vivenciam.

Entende-se, portanto, que esse processo de aprendizagem é a principal contribuição do estudo realizado, viabilizada pela execução de um desenho metodológico que considerou em todas as suas etapas, o caráter político e pedagógico do processo avaliativo.

\section{REFERÊNCIAS}

BRANDÃO, D.B. Avaliação com intencionalidade de aprendizagem: contribuições para avaliação de programas e projetos sociais. 2007. f.85. Dissertação (Mestrado em Educação: Currículo). PUC-SP. São Paulo, 2007. Disponível em: <http://institutofonte.org.br/avalia\%C3\%A7\%C3\%A3o-comintencionalidade-de-aprendizagem>. Acesso em 01 de julho de 2011.

BRASIL. Ministério das Cidades. Secretaria Nacional de Saneamento Ambiental. Formulação do Programa Educação Ambiental e Mobilização Social para o Saneamento. Termo de Referência para celebração de Convênio. Brasília - DF, 2005.

CERVO, A.L.; BERVIAN, P.A.; DA SILVA, R. Metodologia científica. 6 ed. São Paulo : Editora Afiliada, 2006.

MARANHÃO, R. R.; SORRENTINO, M. Educação Ambiental e Mobilização Social em Saneamento. In: BRASIL. Ministério das Cidades. Secretaria Nacional de Saneamento Ambiental. Programa de Modernização do setor de Saneamento (PMSS). Lei Nacional de Saneamento Básico: perspectivas para as políticas e a gestão dos serviços públicos. Livro II. Conceitos, características e interfaces dos serviços públicos de saneamento básico. Brasília: Editora, 2009, p. 425 - 433.

MINAYO, M.C.S. O Desafio do Conhecimento: pesquisa qualitativa em saúde. 4 ed. Rio de Janeiro - RJ: Afiliada /HUCITEC-ABRASCO, 1993.

MINAYO, M. C. S. Construção de Indicadores Qualitativos para Avaliação de Mudanças. Revista Brasileira de Educação Médica. Fundação Osvaldo Cruz, 33 Supl.1, Rio de Janeiro, p. 83-92, 2009. Disponível em:< http://www.scielo.br/pdf/rbem/v33s1/a09v33s1.pdf> Acesso em: 23 de agosto de 2009.

OAKLEY, P.; CLAYTON, A. Monitoramento e Avaliação do Empoderamento. São Paulo: Intituto Pólis. , 2003.

PENNA FIRME, T. Os Avanços da Avaliação no século XXI, 2011. Disponível em <http://www.jurandirsantos.com.br/outros artigos/ea os avancos da avaliaca o do seculo XXI.pdf $>$. Acesso em 10 de julho de 2011. 
RESSEL, L.B.; BECK, C.L.C.; GUALDA, D.M R.; HOFFMANN, I.C.; SILVA, R. M.; SEHNEM, G.D. O uso do grupo focal em pesquisa qualitativa. Revista Texto Contexto Enfermagem. Florianópolis, out-dez, 2008, 779 - 796. Disponível em:< http://www.scielo.br/pdf/tce/v17n4/21.pdf>. Acesso em 22 de junho de 2011.

RIBEIRO, H.; GUNTHER, W.M. R.; ARAUJO, J.M. Avaliação qualitativa e participativa de projetos: uma experiência a partir da pesquisa em educação ambiental e saneamento básico. Revista Saúde e Sociedade, v. 11, n. 2, p. 107-132, 2002. Disponível em:<http://www.scielo.br/pdf/sausoc/v11n2/08.pdf>. Acesso em :15 de setembro de 2009.

RIBEIRO, V.M.; KALOUSTIAN, S (Coord.). Indicadores da qualidade na educação. Ação Educativa, Unicef, Pnud, INEP, Seb/MEC. São Paulo: Ação Educativa, 2007, $3^{\text {a }}$ edição ampliada. Disponível em: < http://portal.mec.gov.br/seb/arquivos/pdf/Consescol/ce indqua.pdf>. Acesso em: 22 de junho de 2011.

SANTANA, J.S.S. A coleta de dados na pesquisa qualitativa. REDET. Bases espistemológicas e metodológicas para o estudo dos determinantes sociais da saúde. Módulos 2a e 2b. Sessão 8. Feira de Santana: UEFS, 2003.

SILVA. C. P. R. Indicadores para avaliação de programas de controle de infecção hospitalar: construção e validação. Epidemiologia e Serviço de Saúde, Volume 16 - № 2 - abr/jun de 2007. Disponível em:< http://portal.saude.gov.br/portal/arquivos/pdf/1lugar mestrado avaliacao progr amas.pdf>. Acesso em 12 de julho de 2011. 